\title{
An Extratropical Air-Sea Interaction over the North Pacific in Association with a Preceding EI Niño Episode in Early Summer
}

\author{
YAFEI WANG \\ State Key Laboratory of Severe Weather, Chinese Academy of Meteorological Sciences, Beijing, China \\ ANTHONY R. LUPO \\ Department of Soil, Environmental, and Atmospheric Sciences, University of Missouri-Columbia, Columbia, Missouri
}

(Manuscript received 16 January 2009, in final form 13 May 2009)

\begin{abstract}
Using data for the month of June from 1951 through 2000, this study examined the air-sea interactions over the North Pacific after El Niño matured during the preceding fall season. The principal findings of this work are the following: 1) a coherent region near the international date line (IDL) in the extratropical North Pacific revealed an area of significant negative correlations (SNCs) between the preceding November sea surface temperature (SST) in the Niño-3 region and the June SST in the North Pacific. Also, two indexes of the June Okhotsk high show a significant positive correlation with the November SST in the Niño-3 region during the 1963-2000 period. 2) The strong southeastward wave flux from the upstream area of the Okhotsk Sea over much of the North Pacific in the midlatitudes is associated with a strong preceding El Niño event, the development of the Okhotsk high, and a negative 500-hPa geopotential height/SST anomaly around the coherent region. The stationary wave propagation plays a major part in maintaining the low SSTs in the coherent region and suppressing the northward progress of the subtropical high. This process partially bridges the connection between the central equatorial Pacific warming (CEPW) and the East Asian summer monsoon. 3) A wave train-like anomaly in the SST (tilted northwest-southeast) was established and maintained in the North Pacific during the summer of 1998. This coincided with the direction of the atmospheric Rossby wave propagation as the strong southeastward wave flux was scattered over the midlatitude North Pacific. This event provides solid evidence that Rossby wave propagation plays an important role in forming an oceanic temperature wave train in the extratropical Pacific through the barotropic process.
\end{abstract}

\section{Introduction}

Air-sea interactions play a key role in understanding climate variations. Bjerknes $(1966,1969)$ introduced a dynamic bridge between the Southern Oscillation and the warming of central and east Pacific sea surface temperatures (SSTs; an El Niño event). In fact, this linkage has established a substantial foundation for seasonal and climate predictions (e.g., Barnston et al. 2005). The East Asian summer monsoon is very different from a South Asian (or Indian) summer monsoon in its response to El Niño-Southern Oscillation (ENSO) events (Wang et al. 2001, hereafter referred to as W01).

Corresponding author address: Dr. Yafei Wang, State Key Laboratory of Severe Weather, Chinese Academy of Meteorological Sciences, 46 Zhongguancun Southern St., Haidian, Beijing 100081, China.

E-mail: yfwang@cams.cma.gov.cn
Ye and Huang (1996) obtained the following result using a composite analysis. They showed that there is a positive precipitation anomaly over the Yangtze River and northeast China in the summer following an El Niño year. ${ }^{1}$ However, since they did not find any significant correlation between ENSO events and the rainfall over the areas they referred to, a composite analysis by itself failed to yield a convincing result. Considering the Ye and Huang (1996) results in detail, the authors of W01 decided to define more precisely a referential summer with regard to an El Niño year. According to Rasmusson and Carpenter (1982), most El Niño phenomena mature by the end of the initial calendar year (fall or winter) in a 2-yr sequence. Therefore, W01 defined an El Niño or a La Niña year only when the sea surface temperatures in

\footnotetext{
${ }^{1}$ An El Niño year here means a calendar year when El Niño matures in autumn or winter.
} 
the Niño-3 region (SST3) reached their highest or lowest value in the fall or winter season. W01 found that a strong (weak) East Asian summer monsoon tends to occur about 4-9 months after the SST3 anomalies exceed $1.5^{\circ} \mathrm{C}$ (below $-0.7^{\circ} \mathrm{C}$ ). Typically, during such a strong East Asian summer monsoon, blocking anticyclones in northeast Asia dominate and the subtropical high appears to extend westward, maintaining its intensity in a position that is farther south than usual. This kind of weather pattern is likely to increase the intensity of precipitation in southern China, as reflected in the composite map of Ye and Huang (1996); however, these authors did not explain why such a delayed circulation change occurs in relation to the preceding El Niño episode. Wang et al. (2000) identified the anticyclonic circulation anomalies located over the Philippine Sea as the key system that bridges the eastern Pacific warming and the East Asian monsoon climate. This anomalous anticyclone becomes established prior to the warm peak in the Pacific and persists until the following summer because of in situ air-sea interaction. Nevertheless, Wang et al. (2000) did not explore the delayed impacts of ENSO on the mid-high-latitude circulation, especially that of the positive height anomalies contributing to the Okhotsk high's development. The Okhotsk high is often a blocking event and plays an important role in suppressing the northward progress of the subtropical high with Rossby wave propagation (Wang 1992; Wang and Yasunari 1994; Wang et al. 2007). In turn, the location and strength of the subtropical high is directly associated with the activity of the East Asian summer monsoon (Chang et al. 2000). These connections represent a dynamic bridge between the tropical and North Pacific Ocean.

On the other hand, there is a long and persistent negative SST anomaly (SSTA) in the extratropical North Pacific in the summer that accompanies a decaying central equatorial Pacific warming (CEPW), as shown in Fig. 8 of W01. Alexander et al. (2002) pointed out that this ENSO-related negative SST anomaly area, especially to the east of the international date line (IDL), can be maintained into the summer mainly due to cold surface heat fluxes after the establishment of a winter atmospheric bridge between the tropical and North Pacific Oceans. However, the low SSTs to the west of the IDL in the extratropical North Pacific obviously appear during summer as well. It is possible that the negative SSTA, which may be due to mainly another physical process occurring in higher latitudes could interact with the overlying atmosphere and influence the circulation around East Asia. An examination of the possible physical process could provide a more reasonable explanation of the impact of a preceding El Niño event on the East Asian summer circulation than that provided by Wang et al. (2000). Thus, this study endeavored to investigate what type of air-sea interactions in early summer (June) occur if a strong El Niño matures in the preceding autumn. The questions to be addressed here include the following:

1) Are there close relationships among the occurrence of the Okhotsk high, the cold water in the extratropical North Pacific, and the preceding matured El Niño event?

2) What role does air-sea interaction play in these relationships?

3) Can these relationships explain the suppression of the northward progress of the subtropical high as a supplement to the Wang et al. (2000) explanation for the impact of an El Niño event on the East Asian summer circulation?

\section{Data}

The National Centers for Environmental PredictionNational Center for Atmospheric Research (NCEPNCAR) global atmospheric reanalysis dataset were the primary dataset used in this study. A detailed description of the data assimilation system that produced this dataset was given by Kalnay et al. (1996). We used the monthly (June 1951-2000) and daily (from 28 May to 8 July for the years 1990-2000) 500-hPa geopotential heights (Z500) on a $2.5^{\circ}$ latitude-longitude grid. We also used SST3 compiled by the NCEP Climate Prediction Center in June from 1951 to 2000. The National Oceanic and Atmospheric Administration (NOAA) Extended Reconstructed SST V2 with a $2^{\circ}$ latitude-longitude grid in June from 1951 to 2000 and weekly NOAA SST V2 with a $1^{\circ}$ latitude-longitude grid from 28 May to 8 July of 1990-2000 were also used (Smith and Reynolds 2004). Note that the number of observations from buoys was small especially over broad regions of the tropical Pacific for the years prior to 1980.

\section{Linkage of the Okhotsk high in June with preceding El Niño episodes}

Wang (1992) examined blocking-high activity during the mei-yu period and noted a close relationship between the occurrence of a blocking anticyclone around the Okhotsk Sea and within the mei-yu period. It is well known that the mei-yu front is a persistent annual precipitation phenomenon distributed over the region from the middle and lower reaches of the Yangtze River of China to the Japan Islands during the early summer (mainly in June). This blocking anticyclone is generally referred to as the Okhotsk high. The statistical result obtained by using $500-\mathrm{hPa}$ weather maps demonstrates 


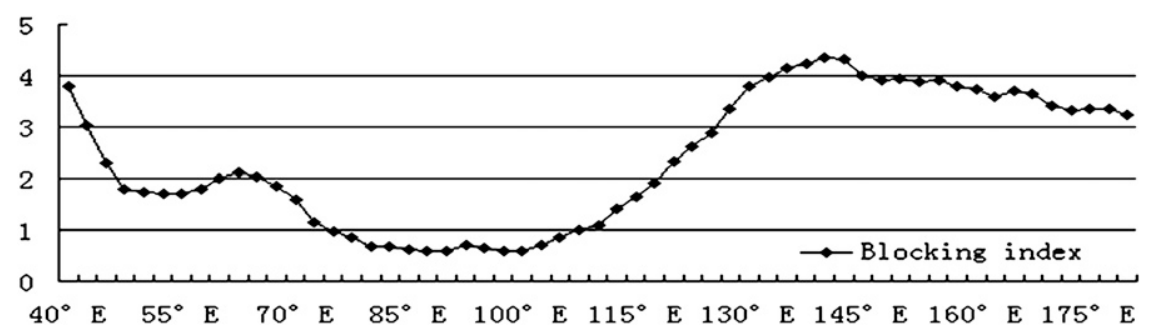

FIG. 1. Average number of days when the circulation was blocked at a given longitude over the Eurasian region in June of 1951-2000.

that this blocking high tends to occur between $50^{\circ}-70^{\circ} \mathrm{N}$ and $131^{\circ}-150^{\circ} \mathrm{E}$ during June and July.

The blocking high is described here by using a blocking index based on the definition of Tibaldi and Molteni (1990), who stated that the blocking index is a coarse-resolution local maximum of the 5-day-averaged $500-\mathrm{hPa}$ height on a given meridian.

The formula is as follows:

$$
\begin{aligned}
& \operatorname{GHG} 1(\lambda, t)=\frac{z\left(\varphi_{0}, \lambda, t\right)-z\left(\varphi_{-}, \lambda, t\right)}{\varphi_{0}-\varphi} \text { and } \\
& \operatorname{GHG} 2(\lambda, t)=\frac{z\left(\varphi_{+}, \lambda, t\right)-z\left(\varphi_{0}, \lambda, t\right)}{\varphi_{+}-\varphi_{0}}
\end{aligned}
$$

where $z$ is the 5-day running mean of geopotential height at $500 \mathrm{hPa}$;

$$
\begin{aligned}
& \varphi_{0}=60^{\circ} \mathrm{N}+\Delta, \\
& \varphi_{+}=\varphi_{0}+20^{\circ}+\Delta, \\
& \varphi_{-}=\varphi_{0}-20^{\circ}+\Delta,
\end{aligned}
$$

and

$$
\Delta=-5^{\circ}, 0^{\circ}, \text { or }+5^{\circ} .
$$

The circulation is judged to be blocked at longitude $\lambda$ and time $t$ and only if

$$
\operatorname{GHG} 1(\lambda, t)>0 \text { and } \operatorname{GHG} 2(\lambda, t)<-10 \mathrm{~m}\left({ }^{\circ}\right)^{-1}
$$

for at least one value of $\Delta$ in (3).
Figure 1 shows the average number of days when the circulation was blocked at a given longitude over the Eurasia region for June of 1951-2000. Note that the figure displays the total number of days at every $2.5^{\circ}$ longitude divided by the 50 Junes roughly representing the climatic occurrence frequency for blocking at that longitude. The maximum is 4.34 days at $140^{\circ} \mathrm{E}$ with a second peak at 3.8 days near $40^{\circ} \mathrm{E}$. This distribution is similar to that shown in Wang (1992), except that Wang (1992) displayed a peak around $100^{\circ} \mathrm{E}$ as well. The longitudinal distribution shown in Fig. 1 is also similar to that found using the June data from Wiedenmann et al. (2002) using their definition for blocking (not shown). Note that the blocking peak near $140^{\circ} \mathrm{E}$ is associated with the occurrences of the Okhotsk high, which is located just inside the study area.

This statistical diagnosis confirms that the Okhotsk high is the large-scale system most frequently appearing over Eurasia in June during the mei-yu period. Furthermore, we produced an index called OKHI-1 for the Okhotsk high by averaging the blocking days from $130^{\circ}$ to $150^{\circ} \mathrm{E}$. Figure 2 shows the time series for OKHI- 1 SSTs in the Niño-3 region during the preceding November (SST3-preNOV). Since the data used here are the monthly means, we chose November as the date when an El Niño tends to mature. This procedure coincides with W01 who found that the East Asian summer circulation is well correlated with the SSTs in the Niño-3 region for the preceding autumn or winter, when an El Niño tends to mature. The values of SST3-preNOV

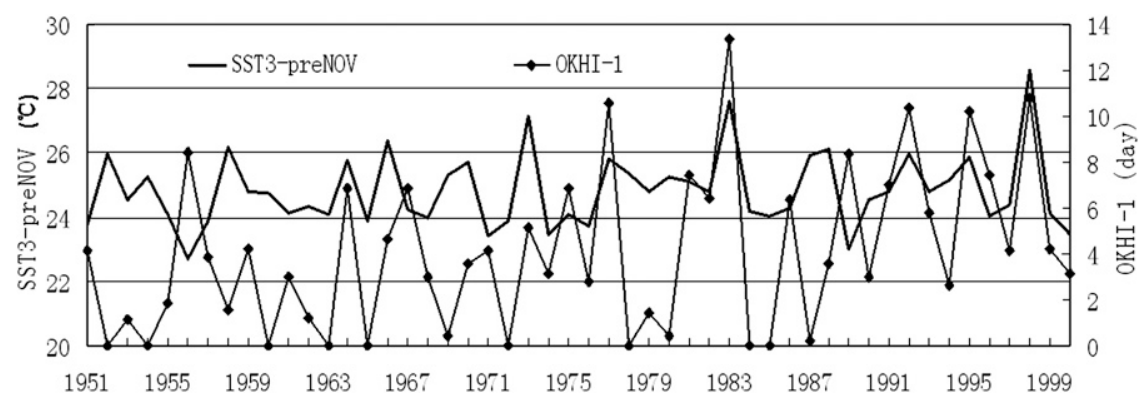

FIG. 2. The evolution of the OKHI-1 (thin solid line) and SST3-preNOV (thick solid line). 

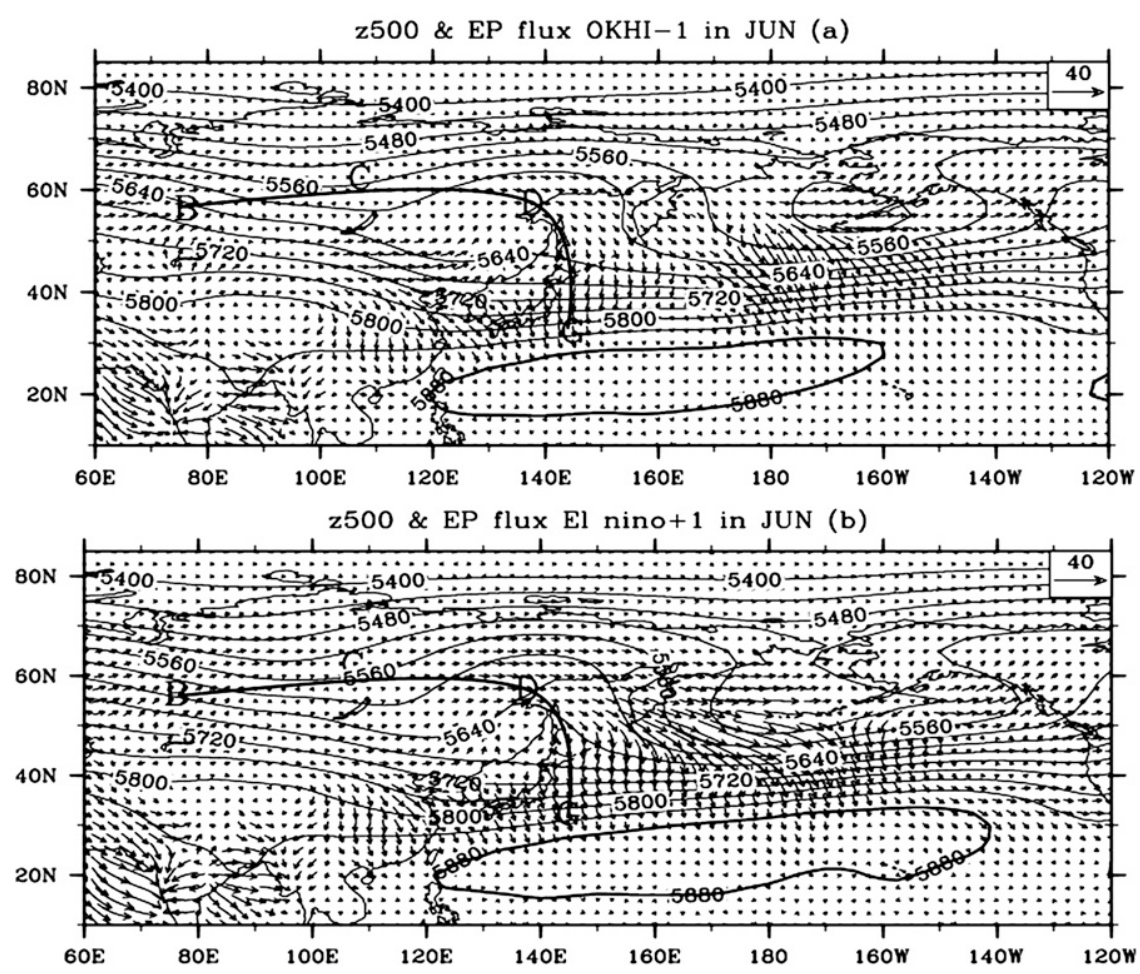

FIG. 3. The composite 500-hPa height and HWAF $\left(\mathrm{m}^{2} \mathrm{~s}^{-2}\right)$ for the months of June (a) when OKHI-1 exceeds 7 days and (b) for months of decaying El Niño years when SST3-preNOV is more than $26^{\circ} \mathrm{C}$. The bold arched line indicates the OKJ propagation route. The line of $5800 \mathrm{gpm}$ is in bold and the contour interval is $40 \mathrm{gpm}$.

are those that appeared in the preceding November (e.g., the $28.55^{\circ} \mathrm{C}$ marked in 1998 actually being that for November of 1997). The two indexes roughly coincide and the correlation coefficient is 0.294 , which exceeds the $95 \%$ confidence level. However, the coefficient between them during the 1951-62 period was -0.76 and during the 1963-2000 period it was 0.43 , and these correlations exceeded the $99 \%$ confidence level. It should be noted that the data from the earlier period may be less reliable than that from the later period since the observation network has improved continuously.

This result may imply that there is interdecadal variability in this relationship. The annual evolution of the OKHI- 1 changed greatly over $50 \mathrm{yr}$. In some years, there was no blocked circulation around the Okhotsk Sea (e.g., 1963 and 1965), whereas, during other years, blocked flows existed frequently (e.g., 1983 and 1998). Note that these later years were those in which the famous El Niño events reached their mature phase during the preceding autumn and winter seasons.

If either 1983 or 1998 was not included, the correlation between them still exceeded $95 \%$ of the confidence level during the period for 1963-2000. However, if both 1983 and 1998 were removed, the correlation between the two indexes was not meaningful during any period. The ENSO events that occurred in 1982/83 and 1997/98 were too strong to be ignored. Although this analysis covered the period from 1950-2000, we have to consider the decadal variation as shown in Fig. 2 in the following study as well.

Since the composites using the high and low values of the indexes largely mirror each other, our description and discussion that follows focuses on the high-value composites. Figure 3 shows the composite 500-hPa height and horizontal wave activity flux (HWAF) for the months of June when OKHI-1 exceeded 7 days (e.g., Fig. 3a: 1977, 1983, 1989, 1991, 1992, 1995, 1996, and 1998) and for those of decaying El Niño years (e.g., Fig. 3b: 1966, 1973, 1983, 1988, and 1998), when the SST3-preNOV was more than $26^{\circ} \mathrm{C}$. This coincides with the definition of an El Niño year in W01. The components for 1956 when the OKHI-1 was 8.4 days and for 1958 when the SST3preNOV was $26.2^{\circ} \mathrm{C}$ were removed from Figs. 3a,b, respectively, because of the possibility of interdecadal variability in these indexes. Of course, during the month of June in a decaying El Niño year, the SSTs do not necessarily reflect the ENSO phase. Note that the decaying El Niño years for a high SST3-preNOV in Fig. 3b also have a higher value of OKHI-1, as shown in Fig. 2. 
The bold arched line in Fig. 3 indicates a popular route for the stationary wave propagation on an intraseasonal time scale in June, called the OKJ propagation route that was transposed from Fig. 3 of Wang et al. (2007). The HWAF was used to indicate the direction and magnitude of stationary wave propagation. A detailed calculation of the HWAF designed by Plumb (1985) was introduced by Wang and Yasunari (1994) and Wang et al. (2007). A strong blocking ridge located around the Okhotsk Sea was the preeminent characteristic in Figs. 3a,b, and indicated a similar circulation pattern in the two composite maps. The ridge composite for the El Niño events (Fig. 3b) was stronger than that for the OKHI-1 (Fig. 3a). This is because a later composite (Fig. 3a) included more samples to be averaged so that the ridge strength was suppressed to some extent. Figure $3 \mathrm{a}$ shows a train of strong HWAF propagating from the upstream area of the Okhotsk Sea via the Pacific east of Japan to the subtropical region, which was along the eastern part of the OKJ route proposed by Wang et al. (2007). The other, a stronger beam separated from the OKJ route at the Okhotsk Sea, scattered southeastward and covered the area between $170^{\circ} \mathrm{E}$ and $150^{\circ} \mathrm{W}$ of the North Pacific in the midlatitudes. Figure $3 \mathrm{~b}$ shows similar signs of this flux, but the scattering area of the southeastward HWAF was stronger such that it covered most of the ocean area of the North Pacific in the midlatitudes. The strongest flux beam appeared near the IDL, and the southern end reached $25^{\circ} \mathrm{N}$. Note that the larger flux area over the North Pacific in the midlatitudes accompanied a deep trough from the Bering Sea to Japan. The main body of the subtropical high as characterized by a 5880 geopotential meter (gpm) contour line appeared as an east-west, slab-sided shape that extended farther southward than usual, ${ }^{2}$ as shown in both Figs. 3a,b. The composites for air temperature and its anomaly at surface and $500 \mathrm{hPa}$ for the June months corresponding to Fig. 3 were also produced respectively (not shown). The temperature ridge around the Okhotsk Sea and the trough over the coherent area coincide with those in Fig. 3 in spite of a slight drift in position. The temperature anomaly centers show the wave train-like pattern accompanying the ridge and trough. These implied an enhanced land-sea temperature contrast that can influence the direction and strength of the Rossby wave propagation. One of the important mechanisms for the development of the Okhotsk high is also land-sea temperature contrast as pointed out by Wang (1992).

\footnotetext{
${ }^{2}$ Generally, the climatic position of the subtropical high is indexed by the east-west ridge axis of the 5880 -gpm contour line that is at about $22^{\circ} \mathrm{N}$.
}

\section{Linkage with SST over the North Pacific in June}

Figures 4a,b show the correlations between OKHI-1 and SST over the North Pacific during June and between SST3-preNOV and SST over the North Pacific for June of 1963-2000, respectively. The correlation is greater than the 0.31 needed to reject the null hypothesis of no correlation at the 0.05 significance level. There are two major significant negative correlation (SNC) areas between $30^{\circ}$ and $50^{\circ} \mathrm{N}$ over the North Pacific as shown in Fig. 4a. The westernmost (i.e., around $140^{\circ}-150^{\circ} \mathrm{E}$ ) is obviously related to a cutoff low that usually occurs in conjunction with a cold-water area in situ and is located to the south of the Okhotsk high and with quasibarotropic structure over the extratropical ocean. The east neighborhood (i.e., the SNC area around the extratropical region near the IDL) coincides with the strong southeastward HWAF shown in Fig. 3a, which is also related to the low accompanying the development of the Okhotsk high. A significant positive correlation area covers the western tropical Pacific, which is only found in the southern part of the main body of the subtropical high. Similarly, a large SNC area close to the IDL (center, $43^{\circ} \mathrm{N}, 165^{\circ} \mathrm{E}$ ) and a positive correlation around the tropical western Pacific can be found in Fig. 4b. The positive or negative correlation centers displayed a wave train structure that is tilted northwest-southeast from the midlatitudes to the tropical ocean, as shown in Fig. 4b. If we calculated the correlation including the data of 195062 , the location of the SNC area for OKHI-1 is partly connected with that for SST3-preNOV, indicating that the two joint areas are characterized by similar circulation (figures omitted). For the sake of brevity, we hereafter refer to the SNC area close to the IDL in Fig. $4 \mathrm{~b}$ as the coherent region. Note that the coherent region was covered with a stronger southeastward wave activity flux, as shown in Figs. 3a,b.

Figures 5a,b show the composite SST anomaly and Z500 anomaly corresponding to Figs. 3a,b, respectively. The climatological time period of June 1979-2000 was chosen for calculating the SST-Z500 anomaly largely to reduce the influence of interdecadal variability. The dark-light shaded areas embedded with thin contour lines indicate a positive-negative Z500 anomaly over 10 or below $-10 \mathrm{gpm}$, and thick lines show the contour of the SST anomaly. The correlation and the composite maps indicate that the preceding strong El Niño episode is closely associated with the development of the Okhotsk high during June and that both phenomena are related, with a negative SST anomaly around the coherent region. This result corresponds with the composite map of W01. Note that the majority of the coherent region area accompanying the negative SSTs is 

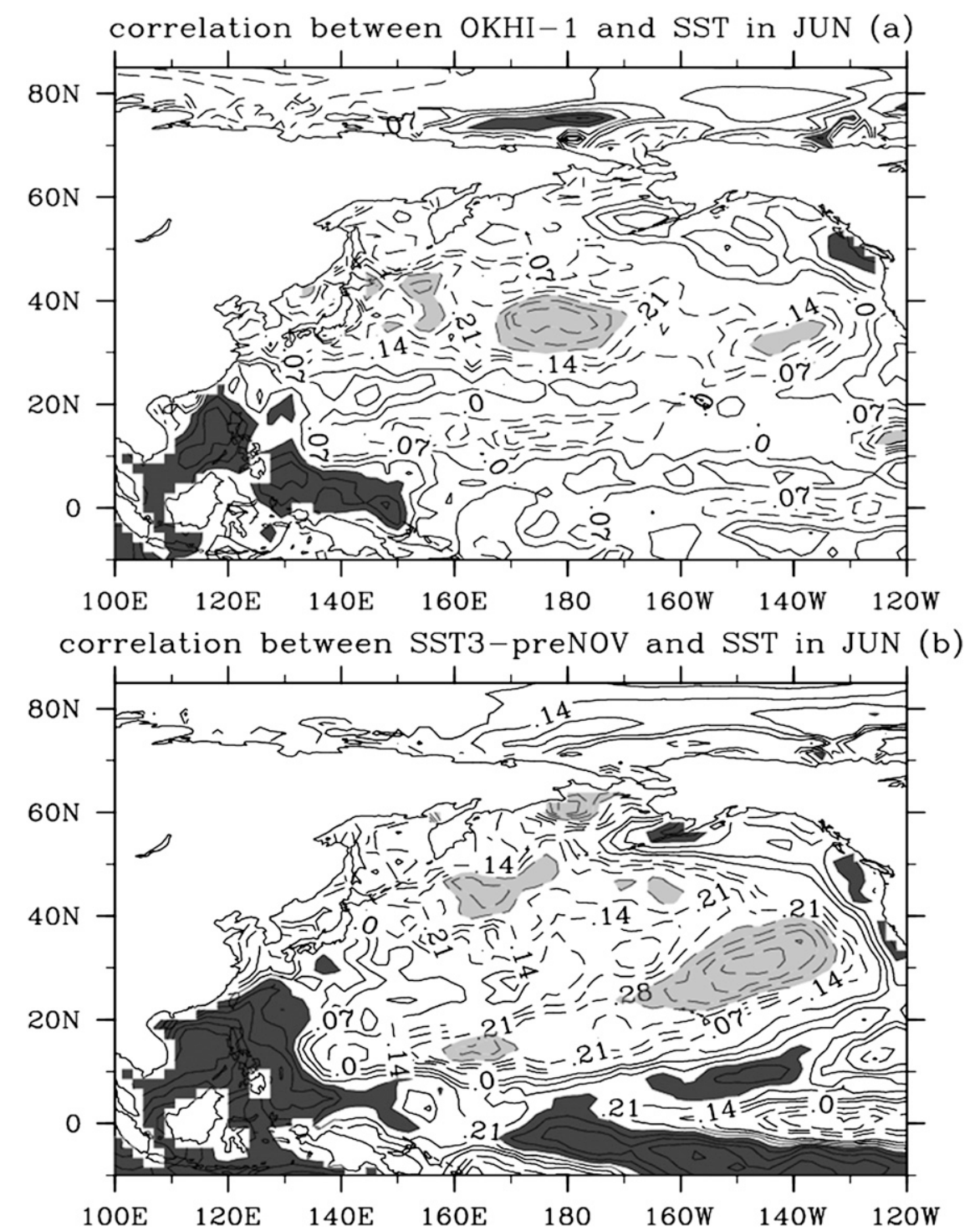

FIG. 4. The correlations (a) between OKHI-1 and SST over the North Pacific in June and (b) between the SST3-preNOV and SST over the North Pacific in June. The contour interval is 0.07 and shaded areas denote the confidence level over $95 \%$.

located to the west of the IDL, displaying a different focus for the cold water area from Alexander et al. (2002). The Z500 and the SST anomalies are distributed with a wave train-like structure over the North Pacific as shown in Fig. 5. Particularly in Fig. 5b, the sign of the wave train of the Z500 anomaly tilted northwestsoutheast appears stronger and more extensive, which coincides with the Rossby waves propagating more robustly from higher to lower latitudes, as shown in Fig. 3b.

Note that the east-west, slab-sided areas of the positivenegative SST anomaly basically coincide with those of the overlying Z500 anomaly over the ocean, except for those over the far Northeast Pacific. Thus it is possible that such a cold-warm wavelike distribution over the northwest Pacific results at least partly from the scattered Rossby wave propagation shown in Fig. 3 through the response of SST to overlying air, as pointed out by Lau (1997). The negative-positive Z500 anomaly areas over the subtropical North Pacific in the composite maps (especially Fig. 5b) dominated the motion of the subtropical high, which was related to the southeastward scattering HWAF (SE-SC-HWAF) and favored the main body of the subtropical high maintaining a position farther southward than usual. Although Wang (1992) and Wang et al. (2007) provided a similar explanation about the stationary wave propagation accompanying the Okhotsk 

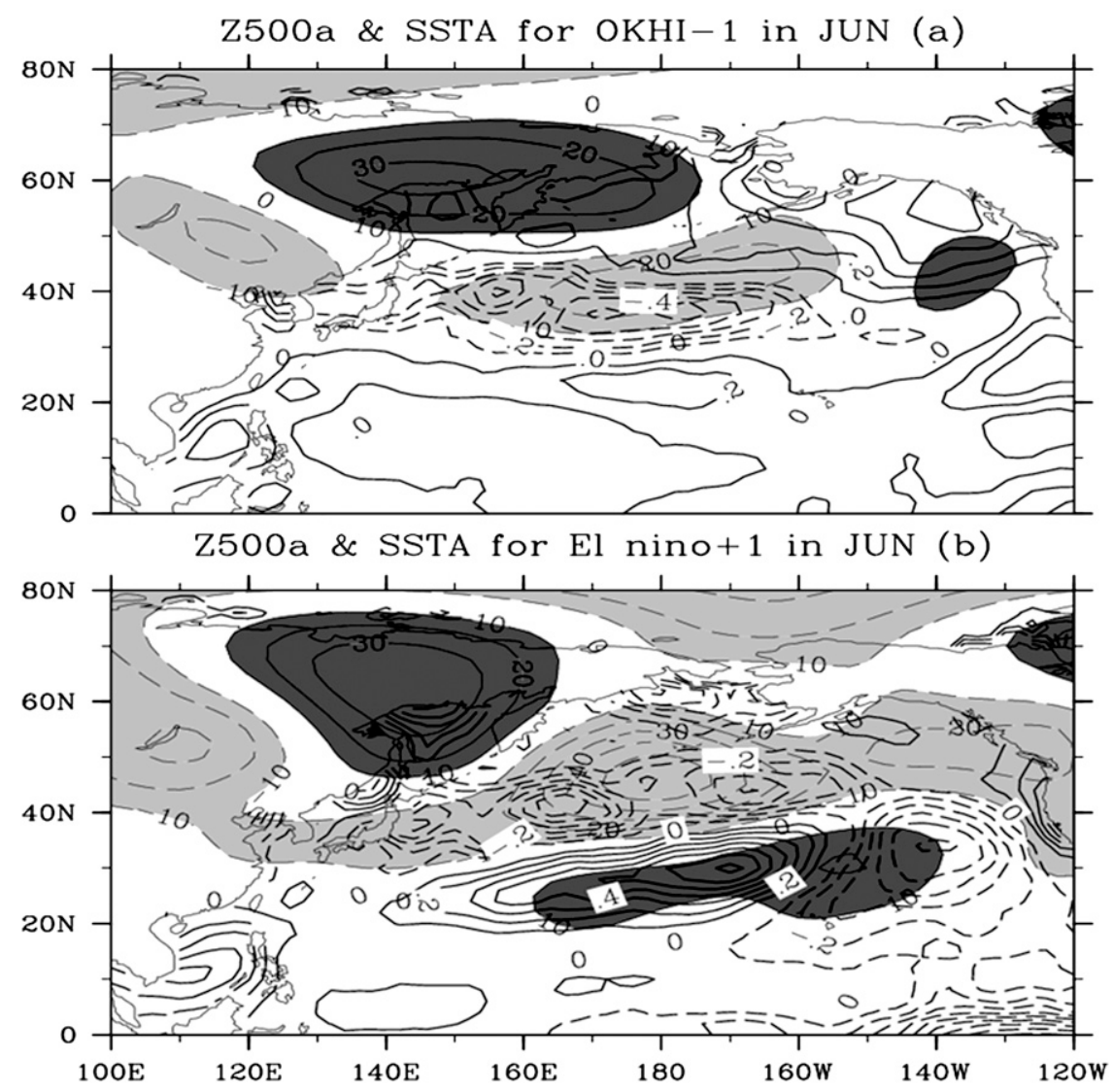

FIG. 5. (a) As in Fig. 3a, but for the composite SST anomaly and Z500 anomaly. (b) As in Fig. 3b, but for the composite SST anomaly and Z500 anomaly. Dark-light shading areas embedded with thin contour line indicate positive-negative Z500 anomaly over 10 or below $-10 \mathrm{gpm}$ and thick lines show the contour of the SST anomaly (interval: $0.2^{\circ} \mathrm{C}$ ).

high, they were limited to focusing on the wave propagation in the narrow OKJ route. The SE-SC-HWAF in the wider scope of the North Pacific can influence the motion of the subtropical high more effectively.

On the other hand, Wang (1992), Nakamura and Fukamachi (2004), and Wang et al. (2007) pointed out that Rossby wave propagation in the upstream area of the Okhotsk Sea (mainly following western OKJ path) is one of the important factors that develop the Okhotsk high. The data were filtered in the 5-10-day band in their analysis. The time scale of the Rossby wave propagation is obviously shorter than that analyzed here. Since the OKJ propagation in the eastern part of the path behaved with a longer decorrelation time scale than that in the west as shown in Wang et al. (2007), the HWAF in the upstream Okhotsk Sea was hidden in the monthly mean field in Fig. 3. However, upstream propagation cannot be omitted for developing the Okhotsk high in spite of the fact that we do not repeat the analysis of the previous study here. Upstream propagation as a mechanism for developing and maintaining blocking events has been demonstrated in numerous studies (e.g., Burkhardt and Lupo, 2005, and references therein). The downstream OKJ-like propagations including the SE-SC-HWAF are the continuation of the upstream, which is also related to the development of the Okhotsk high.

To examine the relationship among the Okhotsk high, ENSO events, and the related SST, we produced some additional indexes called the OKHI-2, SST in the Niño-3 region in the preceding autumn (SST3-preSON), and SSTcoJUN in 1951-2000. The OKHI-2 is the monthly mean of the $\mathrm{Z} 500$ averaged within the region $50^{\circ}-70^{\circ} \mathrm{N}$, $130^{\circ}-140^{\circ} \mathrm{E}$ and during June. The selected area for the index is based on the region with the highest frequency for the occurrence for the Okhotsk high, as pointed out by Wang (1992). Note that a high OKHI-2 does not mean that a blocking high persists around the Okhotsk Sea during the referenced month exactly; rather, it roughly represents the higher activity of blocking highs in situ during the month. The SSTcoJUN is the SST at the common point $\left(38.5^{\circ} \mathrm{N}, 173.5^{\circ} \mathrm{E}\right)$ in June, which is the coexisting point for the SNC and for the OKHI-1 and 
TABLE 1. Correlation coefficients between the indexes during 1951-2000. Bold entries and bold entries with asterisks indicate values exceeding $95 \%$ and $99 \%$ confidence levels, respectively.

\begin{tabular}{lccccc}
\hline \hline & OKHI-1 & OKHI-2 & SST3-preSON & SST3-preNOV & SSTcoJUN \\
\hline OKHI-1 & $\mathbf{1 . 0}$ & $\mathbf{0 . 6 4 *}$ & $\mathbf{0 . 2 8}$ & $\mathbf{0 . 2 9}$ & $-\mathbf{0 . 3 2}$ \\
OKHI-2 & & $\mathbf{1 . 0}$ & 0.24 & 0.21 & $-\mathbf{0 . 3 8}$ \\
SST3-preSON & & & $\mathbf{1 . 0}$ & $\mathbf{0 . 9 9 *}$ & $-\mathbf{0 . 3 2}$ \\
SST3-preNOV & & & & $\mathbf{0 . 0}$ \\
SSTcoJUN & & & & & $\mathbf{1 . 0}$ \\
\hline
\end{tabular}

SST3-preNOV during 1951-2000 but not for the SNC during 1963-2000. SST-p1 and SST-p2 are the SST points at $37^{\circ} \mathrm{N}, 175^{\circ} \mathrm{E}$ and $43^{\circ} \mathrm{N}, 165^{\circ} \mathrm{E}$ that are the center points of the SNCs in Figs. 4a and 4b, respectively. The correlation coefficients among them during 1951-2000 and 1963-2000 are given in Tables 1 and 2, where bold numbers and bold numbers plus star mark show that the confidence level is above $95 \%$ and $99 \%$, respectively. Most indexes significantly correlate with each other, especially the SSTcoJUN, which has a significant correlation with other indexes as shown in Table 1. In spite of smaller coefficient between SST3-preNOV and OKHI-2 (0.209), more significant correlation between SST3preNOV and OKHI-1 (0.294) was found. On the other hand, the recent correlation coefficients between SST3preNOV/SON and OKHI-1 have reached 0.44 and 0.4 exceeding the $99 \%$ confidence level as shown in Table 2. These correlations strongly indicate the importance of blocked circulation characterizing Okhotsk high that tends to appear with previous CEPW. It is well known that the variation of atmospheric circulation in East Asian summer was controlled by many other events (e.g., teleconnections from synoptic to decadal time scale, except for the CEPW). Thus, the correlation from the unfiltered monthly data reaching $99 \%$ confidence level was rather robust. Although less significant correlations for the SST-p1 and SST-p2 with respective indexes were found in Table 2, the coefficient between the SST-p1 and SST-p2 was 0.61 largely surpassing the $99.9 \%$ confidence level. Since SSTcoJUN shows a significant correlation with the other indexes during 19502000, the SST covering the two SNC centers shown in Figs. 4a,b has a weak but notable relationship with the development of the Okhotsk high and previous ENSO events. This also implies that the SE-SC-HWAF emanating from the Okhotsk high plays an important role in maintaining the negative SSTA in the coherent region.

\section{Case Study for $1997 / 98$}

A famous flooding event occurred during the East Asian summer of 1998. Although Wang et al. (2007) examined this 1998 case, they concentrated on the interaction between Rossby waves in the intraseasonal time scale for July 1998. The situation in June was quite different from that in July. Figure 6 shows the evolution of the SST anomaly in the Niño-3 region (SSTA3) and the SST anomaly at the point $\left(41^{\circ} \mathrm{N}, 170^{\circ} \mathrm{E}\right.$; SSTALOW) from June 1997 to July 1998. Both indexes had a sequential increase roughly from the beginning of summer to the end of 1997 . The SSTA3 peaked at $+3.7^{\circ} \mathrm{C}$ in November indicating one of the strongest El Niño mature phases in the last century, and SSTLOW peaked at $+0.6^{\circ}$ in December, Both indexes successively dropped to their lowest values in June or July of 1998. Note that the SSTALOW persisted with a low value below $0^{\circ} \mathrm{C}$ from February through June of 1998, and the lowest value was $-1.44^{\circ} \mathrm{C}$.

Figure 7 shows the distribution of blocking days, similar to Fig. 1, but only for June 1998. The peaks were located at $140^{\circ} \mathrm{E}$ with 14 days and around $55^{\circ}-65^{\circ} \mathrm{E}$ with 7 days. The eastern peak $\left(\sim 140^{\circ} \mathrm{E}\right)$ coincided with that in Fig. 1 but appeared much more robust, indicating that the Okhotsk high was very active during June of 1998. Figures 8 and 9 show Z500 and the HWAF and the Z500 anomaly and SST anomaly for June of 1998,

TABLE 2. As in Table 1, but for the period during 1963-2000.

\begin{tabular}{|c|c|c|c|c|c|c|}
\hline & OKHI-1 & OKHI-2 & SST3-preSON & SST3-preNOV & SST-p1 & SST-p2 \\
\hline OKHI-1 & 1.0 & $0.69 *$ & $0.4^{*}$ & $0.44 *$ & $-0.46^{*}$ & -0.15 \\
\hline OKHI-2 & & 1.0 & 0.37 & 0.36 & $-0.43^{*}$ & -0.25 \\
\hline SST3-preSON & & & 1.0 & $0.99 *$ & -0.21 & -0.39 \\
\hline SST3-preNOV & & & & 1.0 & -0.20 & $-\mathbf{0 . 3 7}$ \\
\hline SST-p1 & & & & & 1.0 & $0.61 *$ \\
\hline SST-p2 & & & & & & 1.0 \\
\hline
\end{tabular}




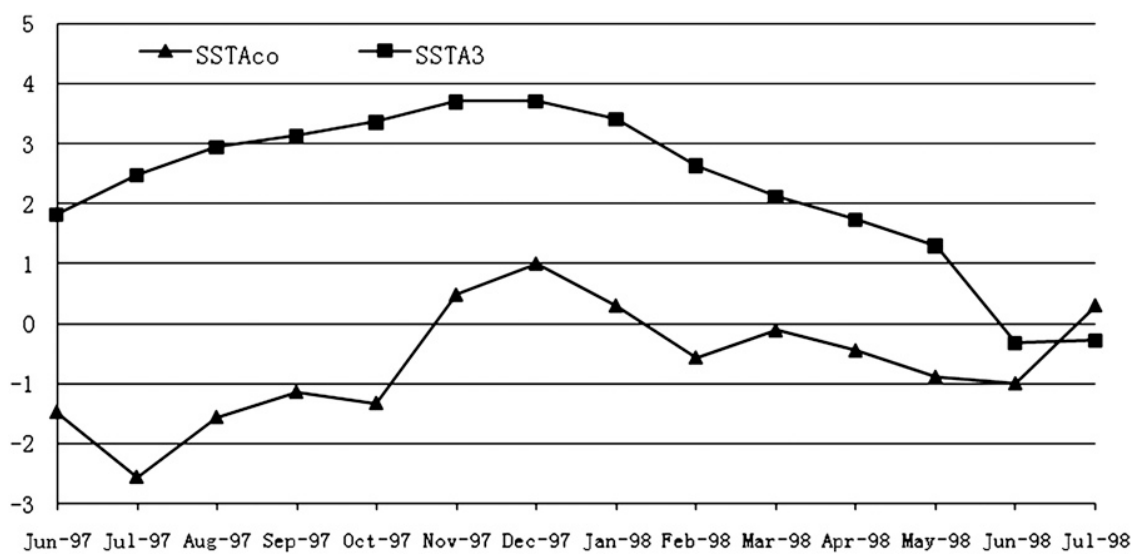

FIG. 6. The evolution of SSTA3 and the SST anomaly at the common point (SSTAco) from April 1997 to July $1998\left({ }^{\circ} \mathrm{C}\right)$.

respectively. A strong blocking ridge was located around the Okhotsk Sea and the main body of the subtropical high kept farther southward than usual, with a negative Z500 anomaly center (below $-20 \mathrm{gpm}$ ) around the coherent region. This situation is indeed similar to that in Fig. 3 but appears much more robustly. Note that the strong southeastward HWAF was scattered over the midlatitudes of the northwest Pacific. This is where the negative SST anomaly also existed over the coherent region, which is similar to Fig. 3 though the main dominating area moved eastward.

Figures 10 and 11 showed the weekly Z500 contour lines with its HWAF and SSTA from 28 May to 8 July 1998, respectively. It is very clear that the strong SE-SCHWAF dominated over the North Pacific, covering the coherent region during the first two weeks of June. A cyclonic low deepened in situ. But the direction of the HWAF changed to northeastward with the Okhotsk high, expanding eastward in the following weeks and indicating a wave phase change. On the other hand, the negative SSTA area east of Japan (around $40^{\circ} \mathrm{N}, 160^{\circ} \mathrm{E}$ in the coherent region) kept its intensity for the first two weeks and then was intensified with a southward shift during the following two weeks. The intensity of the negative SSTA in the coherent region in the third and the fourth weeks can be regarded as a response to the SE-SC-HWAF in situ. The negative SSTA weakened and disappeared during the remaining weeks and the SESC-HWAF never appeared again. This is important evidence that the atmospheric circulation affected SSTA. Compared with Fig. 8, the strong SE-SC-HWAF during the first two weeks accounted for the large majority of it (maxima are over $100 \mathrm{~m}^{-2} \mathrm{~s}^{-2}$ ) in June. Note that an eastward HWAF in the upstream of the Okhotsk Sea, which is one of the causes of the development of the Okhotsk high, obviously appeared in the second, third, and fourth weeks.

\section{Discussion}

Both the statistical and case study analyses demonstrated that when a strong El Niño event matures in

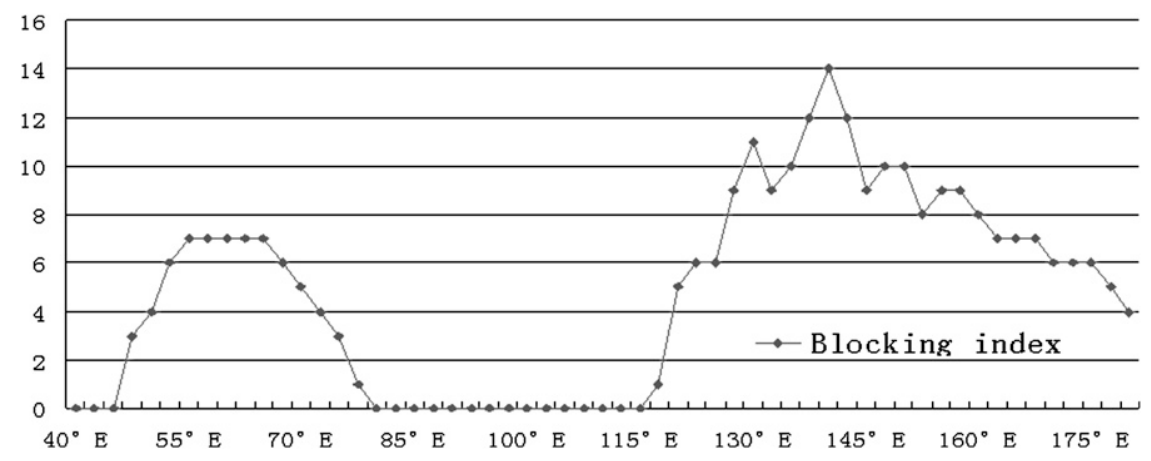

FIG. 7. As in Fig. 1, but for June 1998. 


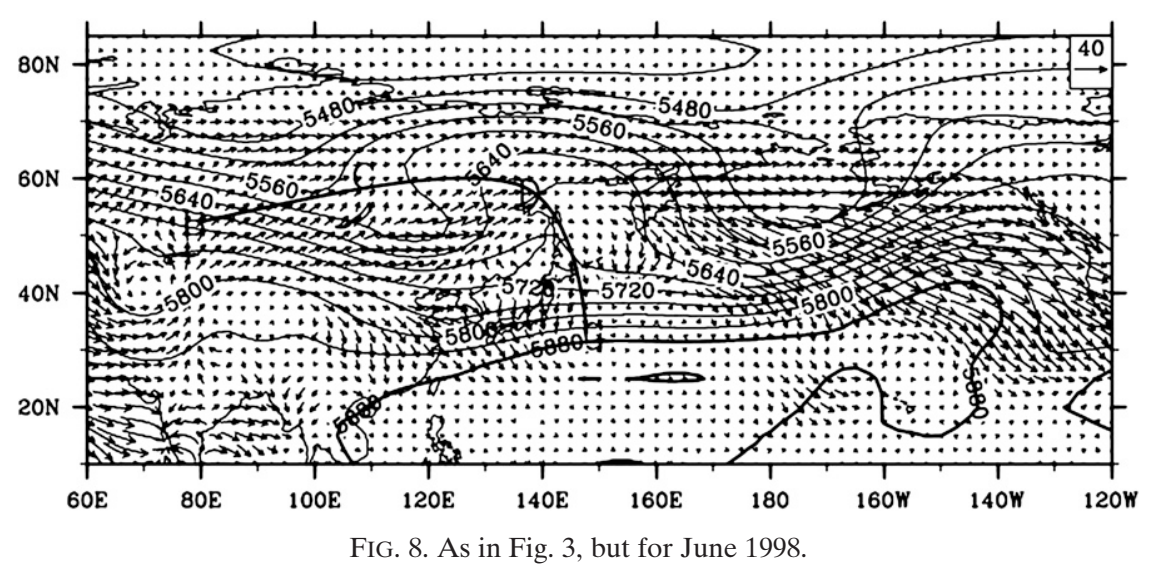

autumn to winter seasons, a strong Okhotsk high, the cold SSTs in the midlatitude of the northwest Pacific, and the SE-SC-HWAF in situ tend to occur in conjunction, and the northward progress of the subtropical high is largely suppressed during the early summer of the following calendar year. This strongly supports the findings of W01.

The maintenance mechanism found in our observation can be summarized as follows. The cold SSTs in central North Pacific, especially to the east of IDL, can persist into the next summer after the peak winter phase of an El Niño event because of the maintaining mechanism of the surface heat flux as pointed out by Alexander et al. (2002). The low SST in situ accompanies an overlying low, forming a quasi-barotropic background climatic state in situ. The related land-sea temperature contrast was intensifying, which contributes a positive feedback to the development of the Okhotsk high. Thus, there must be OKJ propagation that plays an important role in maintaining the blocking high dominating upstream (e.g., Wang 1992).

And then, the downstream OKJ propagation, which is to the east of the Okhotsk Sea, tends to scatter southeastward covering the coherent region with a cyclonic low in the basic climatic background. The generated SE-SCHWAF results in or maintains an underlying cold water area through the air-sea interaction as discussed in section 5. Note that the cold water in the coherent region lies mainly to the west of the IDL, indicating a different area from that found in Alexander et al. (2002) whose work was based on the original atmospheric response to ENSO in the Pacific--North American (PNA) pattern.

But, the SE-SC-HWAF can obviously affect quite a large fraction of the area Alexander et al. (2002) focused on in keeping lower SSTs in situ as well. This new mechanism can be regarded as a supplement of the one proposed by Alexander et al. (2002) for the maintenance of lower SSTs in the central North Pacific.
Since a few El Niño events may dominate the statistical results, more composites were done. The El Niño episodes were then defined by the successive high SSTA3 that reached over $0.8^{\circ} \mathrm{C}$ during November. The shorter or longer El Niño events were divided by those for which the high SSTA3 dropped to below $0.5^{\circ} \mathrm{C}$ before or after the following March, respectively. Figures 12a,b are similar to Fig. 3b except for the intensity of the ridge in Junes that followed shorter (1964, 1966, 1970, 1973, 1977, 1988, and 1995) and longer El Niño events (1983, 1987, 1992, and 1998), respectively. Although both figures show a ridge around the Okhotsk Sea and a trough in the east, the ridge and trough appear stronger in Fig. 12b. In addition, the situation including the HWAF propagation shown in Fig. 12b is more similar to that in Fig. 3b, than compared with Fig. 12a. Most warm events in the above definition were followed by cold ENSO conditions (i.e., 1964, 1966, 1970, 1973, 1983, 1988, 1995, and 1998). The composite maps for the above Junes and the Junes (1977, 1987, and 1992) following other warm events were also produced (not shown). Both composite figures are similar to each other except that the former composite is more similar to Fig. $3 \mathrm{~b}$ as well. Note the

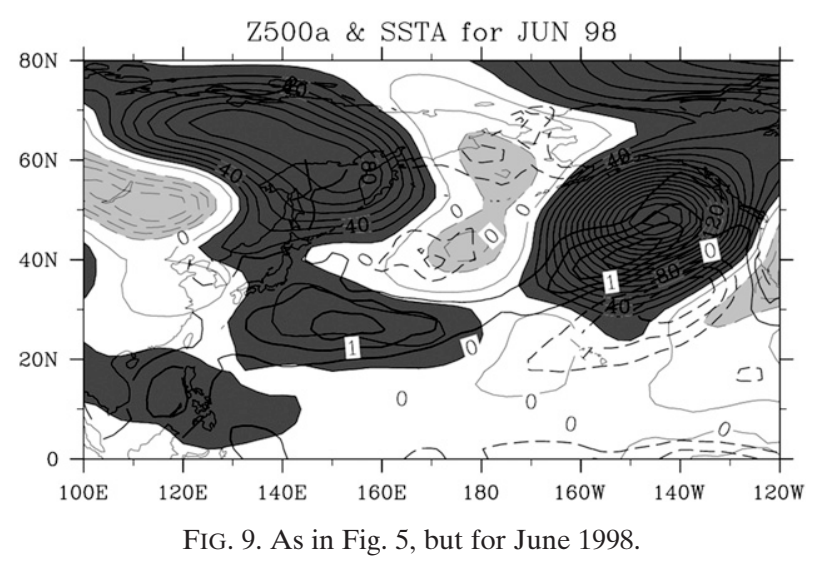


EP flux \& 2500 28Nay -3Jun 98(a)

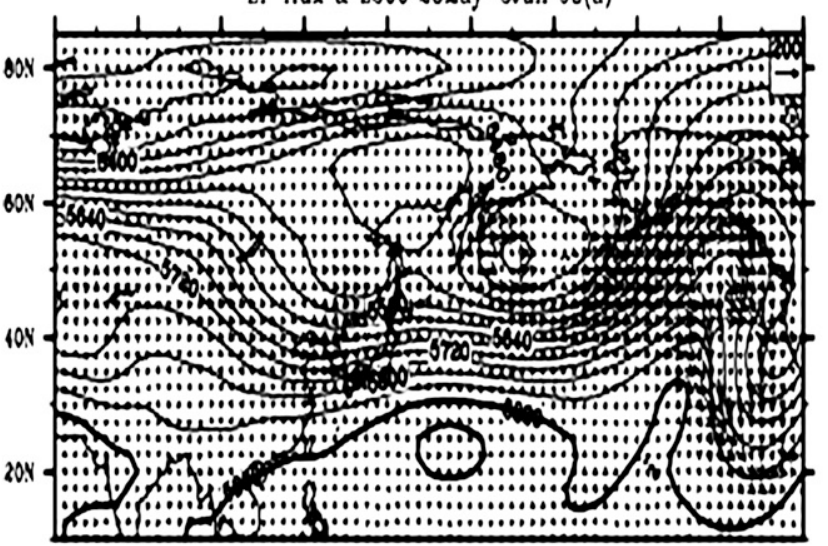

EP flux \& $750011-17$ Jun $98(c)$

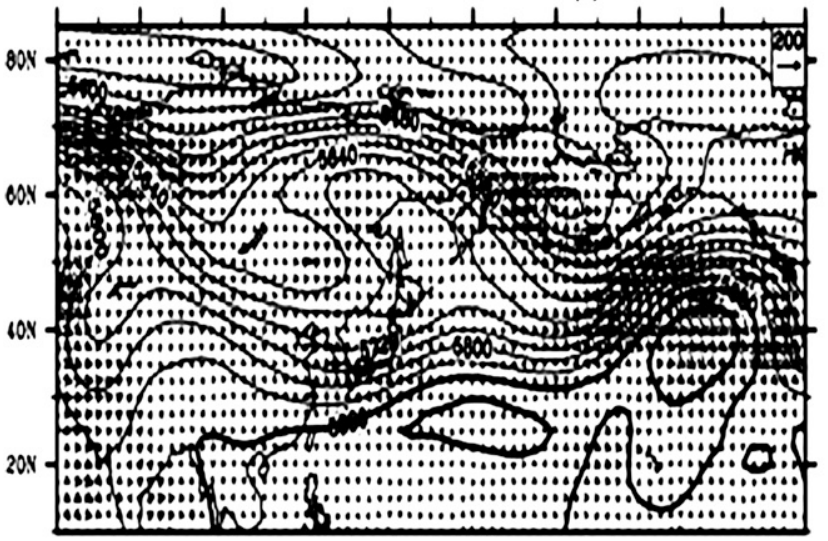

EP Mlux \& 2500 2SJun- IJul $98(e)$

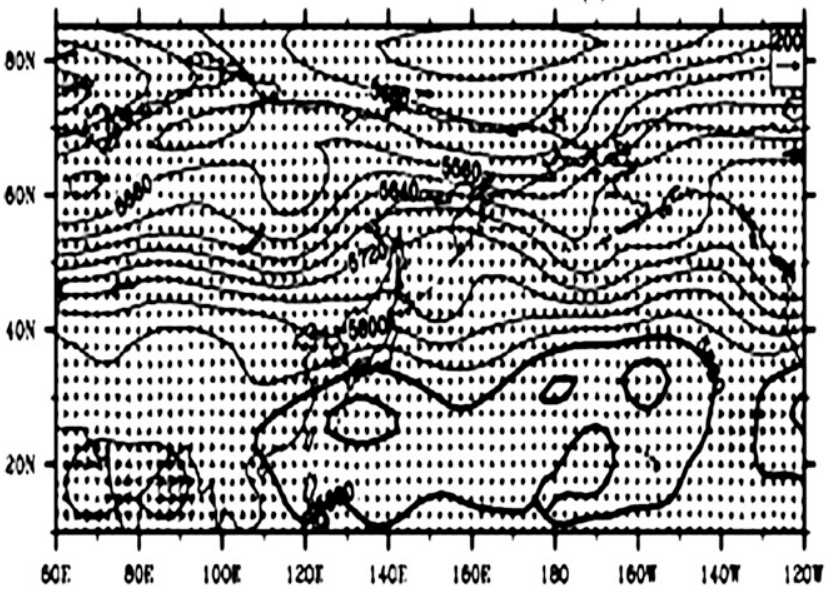

EP flux \& 2500 1-10)un $88(b)$

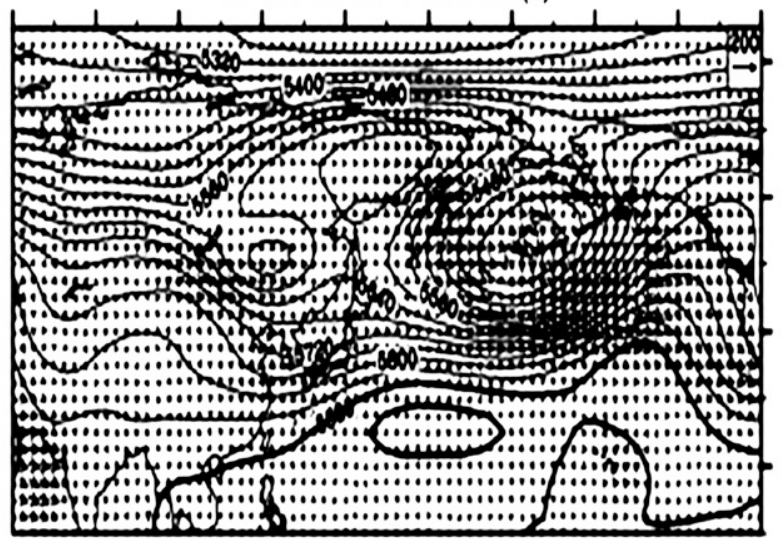

EP flux \& $7,500 \quad 18$-24Jun 98 (d)

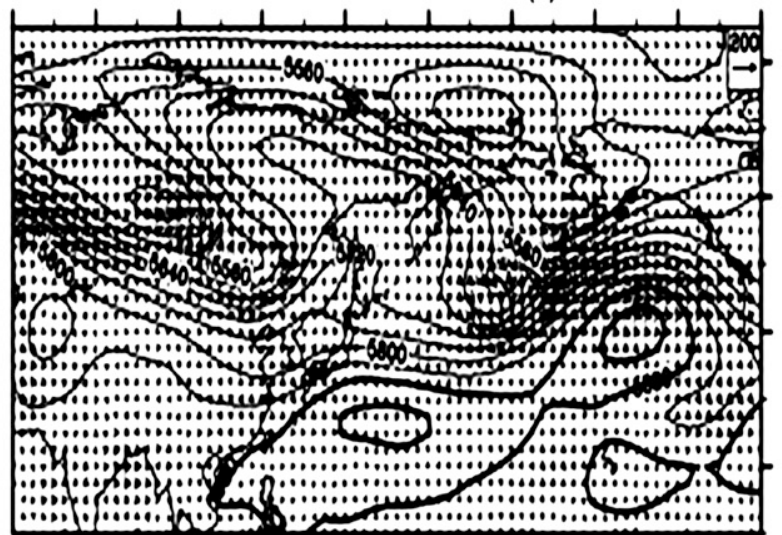

EP flux \& 2500 2-8Jul 8B(I)

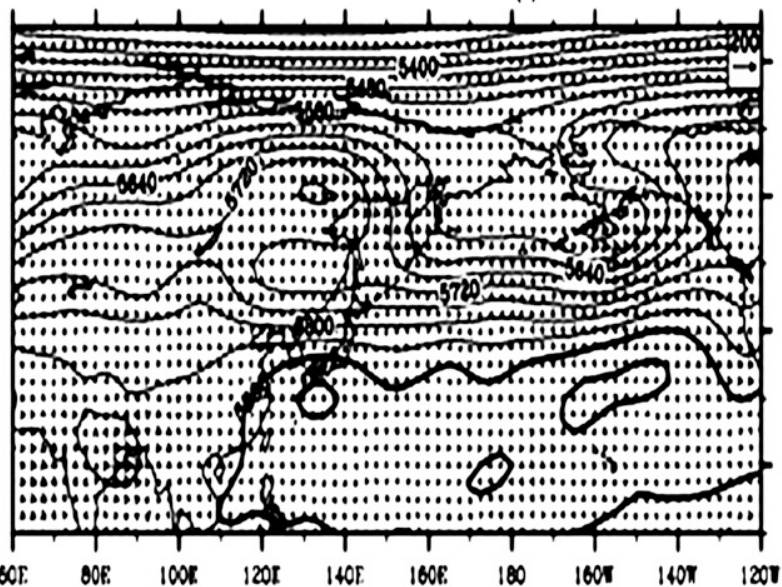

FIG. 10. As in Fig. 3, but for the weekly distribution from 28 May to 8 Jul 1998

former composite obviously includes the cases composed in Fig. 3b. The above composites implied that the high-latitude pattern evolves along with El Niño, and continues to evolve following it. The longer persistence of El Niño tends to be followed by the specific circulation pattern as shown in Fig. $3 b$.
Shaman and Tziperman (2005) pointed out that the PNA pattern usually behaves as a stationary wave that could dominate in most parts of the extratropical atmosphere of the Northern Hemisphere and persists for very long time. The stationary wave would form a natural internal mode that may help to maintain the east 

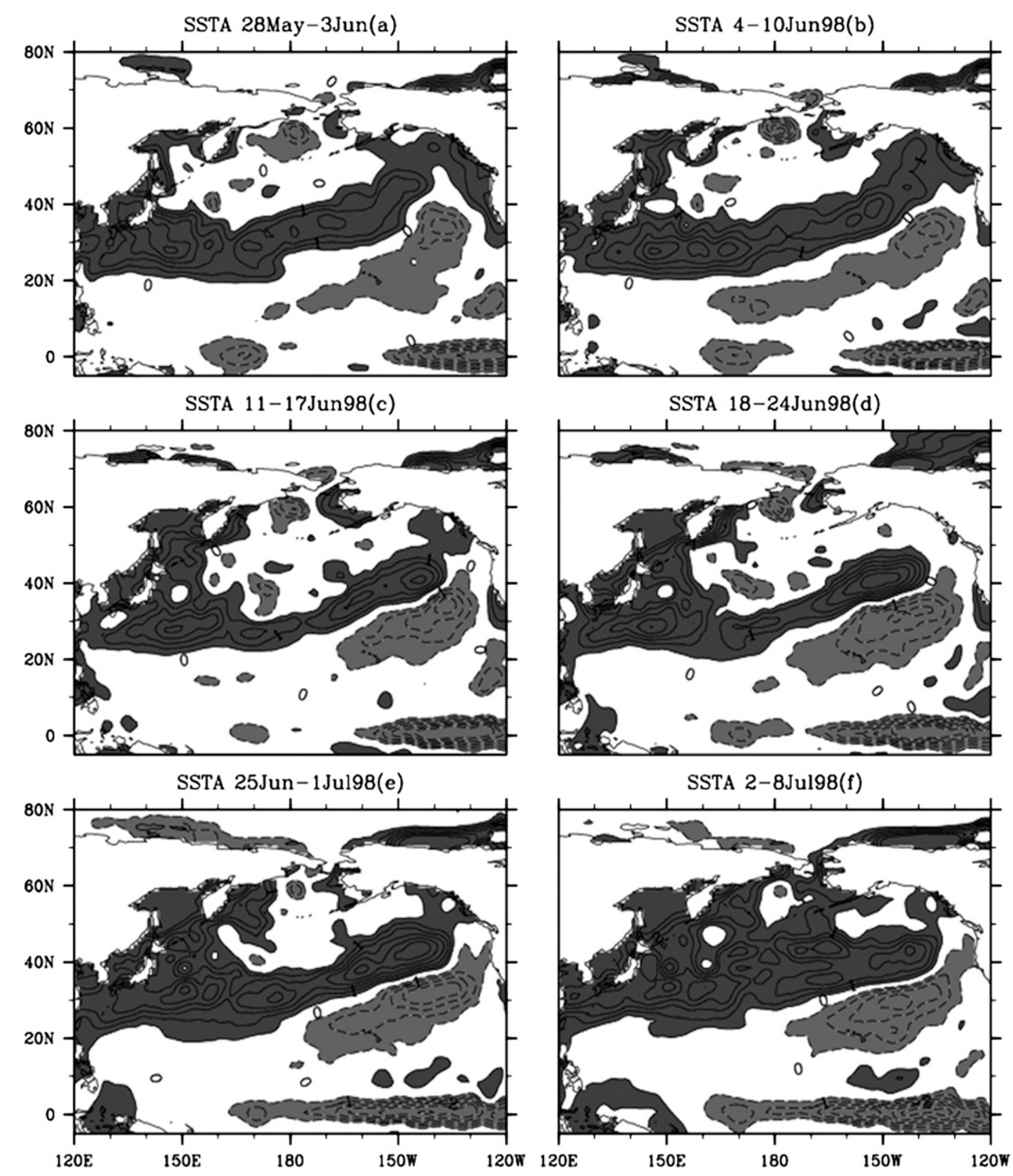

FIG. 11. As in Fig. 10, but for the distribution of the weekly SSTA (interval: $0.5^{\circ} \mathrm{C}$ ). Dark-light shading areas indicate the positive-negative SST anomaly regions.

part of the OKJ-like wave train (mainly from the Baikal Lake via the Okhotsk Sea to the sea area east of Japan) in the early part of the following summer. This is because the eastern part of OKJ propagation may be forced from other sources except for the main source around the Caspian Sea as pointed out by Ogi et al. (2004) and Wang et al. (2007). The supposition for the complicated mechanism needs to be confirmed by further research.

The role of heating over the extratropical region is not simple. General circulation models (GCMs) are the only reliable tool that has widely been used in simulating and explaining various physical processes of air-sea interaction now. The simulations show that the linear impact of the tropical ocean thermal forcing on the local atmospheric circulation is much greater than that of the thermal forcing in the extratropical ocean (Frankignoul 1985). However, atmospheric responses to thermal forcing in the extratropical ocean occur with other processes. Kushnir et al. (2002) provides a more detailed review of the atmospheric GCM response to extratropical SST 

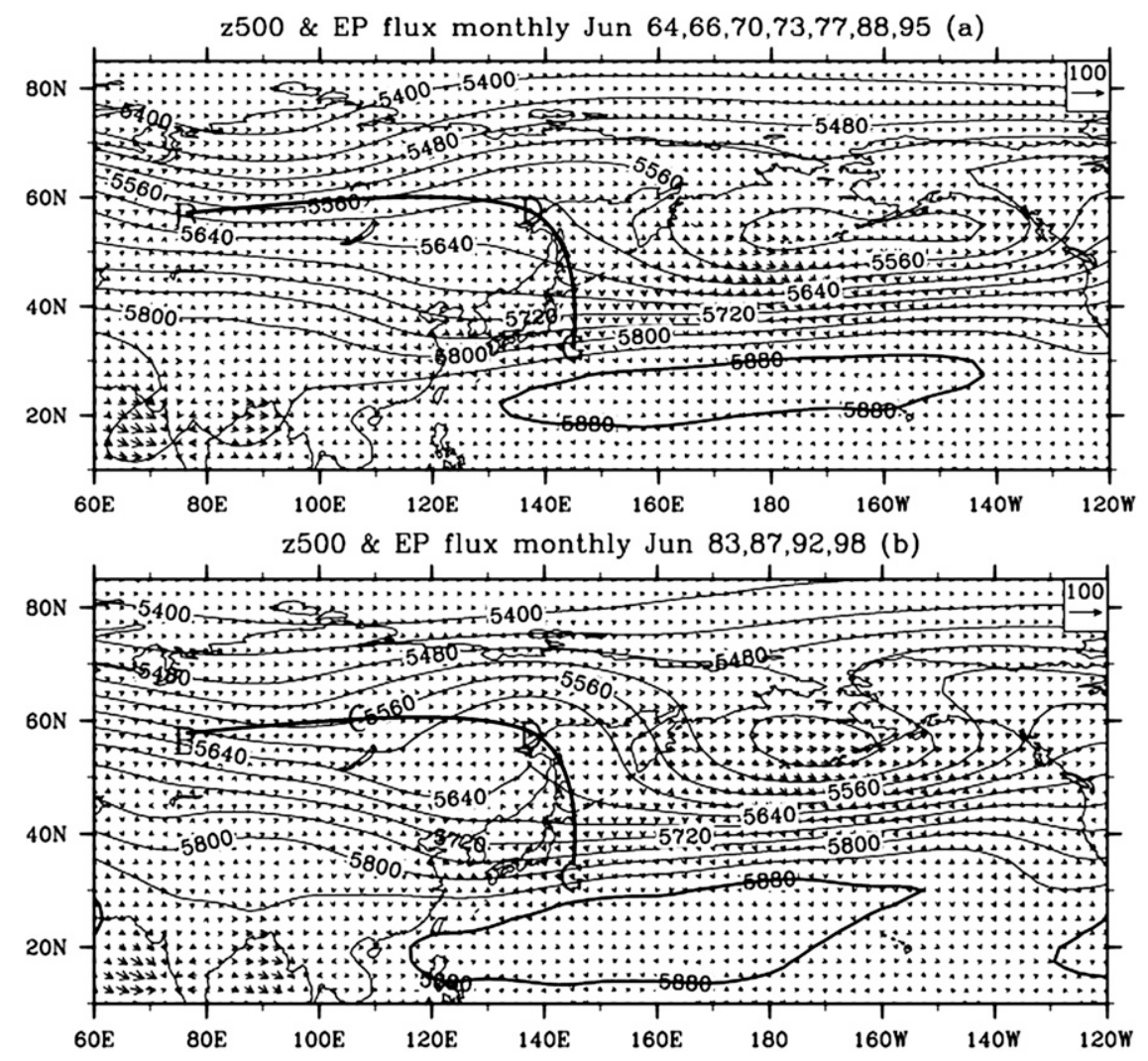

FIG. 12. As in Fig. 3b, but for the Junes following (a) shorter and (b) longer El Niño events.

anomalies. The atmospheric response to the SSTs in the extratropical region cannot be ignored, but it occurred in a very different way from that in the tropical ocean. It mainly included two aspects in one physical process (i.e., nonlinear and linear). As for the former, Webster and Holton (1982) and Held et al. (1989) suggested that a physical explanation for the atmospheric response to the anomalous extratropical SST through a barotropic process by an induced upper-level divergence of the transient eddy vorticity flux. They pointed out that this kind of nonlinear phenomenon belongs to atmospheric internal oscillations, but is enhanced by SST forcing. Peng et al. (1995) found that the response depends on the underlying model's climatic state. The linear response is a thermodynamic interaction. Hoskins and Karoly (1981) and Hendon and Hartmann (1982) proposed that first, low-frequency variability induces an anomalous SST, and second, a surface thermal damping occurs through the SST adjustment. Both barotropic impacts play an important role in maintaining the stationary eddy. What is discussed here is more likely a result of an oscillation of the internal atmosphere through the air-sea interaction in the barotropic process, as pointed out by these authors. The low SST in the coherent region can play an important role not only in maintaining the overlying cyclonic low but also the SE-SC-HWAF in situ (as discussed in next paragraph) although we do not analyze it in detail here.

This kind of scattering propagation is thought to contribute to the wave train-like structure of the SST anomaly through an air-sea forcing, as pointed out by Lau (1997). The lower SST with overlying low heights around the key ocean area appears to be indicative of the scattering propagation, because the stationary wave activity flux tends to connect high and low height centers such as the Okhotsk high and the low around the coherent region. As analyzed in section 5, the lower SST in the coherent region was enhanced by the SE-SC-HWAF in the time scale of a week, indicating a strong response to atmosphere. Another noticeable sign is that the wave train associated with the SST anomaly crossing the North Pacific occurred after June 1998, which is when the scattering propagation appeared (figures for May and late July omitted). This implies a delayed response for the ocean to the overlying atmosphere. It is possible that such a wave train response may extend to the vicinity of the tropical region (e.g., close to the Niño-3 region) through an oceanic dynamic process. However, 
the effect of the wave train associated with the SSTs in the tropical region is quite small (as shown in Fig. 5), and cannot be compared with the influence of the oceanic Rossby and Kelvin waves over the tropical Pacific proposed by McCreary (1983). Further study of the wave train response is needed.

\section{Conclusions}

Based on the statistical and composite analyses above, the results of this study are summarized below:

1) A coherent region near the IDL in the extratropical North Pacific revealed an area of significant negative correlation between SST3-preNOV and the SST in the North Pacific in June. The coherent region is just close to the area of SNC between OKHI-1 and the SST in June. The indexes of OKHI-1 and OKHI-2 in June are positively correlated with the SST3-preNOV during 1963-2000 (exceeding the 99\% confidence level).

2) Strong SE-SC-HWAF from the upstream area of the Okhotsk Sea covering a large fraction of the North Pacific in the midlatitudes is associated with a strong preceding El Niño (i.e., a high SST3-preNOV), the development of the Okhotsk high (high OKHI-1 and OKHI-2), and a negative Z500-SST anomaly around the coherent region. The scattering stationary wave propagation plays a strong part in maintaining the low SST in coherent region and suppressing the northward progress of the subtropical high. The above process is one of the ways that bridges the CEPW and the East Asian summer monsoon circulation, which is a supplement to the physical explanation by Wang et al. (2000).

3) A wave train-like anomaly of the SST (tilted northwest-southeast) was established and maintained for more than two months in the North Pacific in the summer of 1998. This coincided with the direction of the atmospheric Rossby wave propagation as the strong wave activity flux southeastward scattered over most areas of the North Pacific in the midlatitudes. This provides firm evidence that such an atmospheric Rossby wave propagation plays an important role in forming an oceanic temperature wave train in the extratropical Pacific through a barotropic process.

Acknowledgments. We thank the editor, the chief editorial assistant Mary Golden, and the two anonymous reviewers for their valuable suggestions and comments. We also thank Ms. Yan Li for the figure drawing. This study was supported by the project of the Ministry of Science and Technology of China (2004CB418300), National Natural Science Foundation of China (40675034), and the China-Japan intergovernmental cooperation program of the Japan International Cooperation Agency (2008LASWZF01 and 2008LASWI04).

\section{REFERENCES}

Alexander, M. A., I. Blade, M. Newman, J. R. Lanzante, N. C. Lau, and J. D. Scott, 2002: The atmospheric bridge: The influence of ENSO teleconnections on air-sea interaction over the global oceans. J. Climate, 15, 2205-2231.

Barnston, A. G., A. Kumar, L. Goddard, and M. P. Hoerling, 2005: Improving seasonal prediction practices through attribution of climate variability. Bull. Amer. Meteor. Soc., 86, 59-72.

Bjerknes, J., 1966: A possible response of the atmospheric Hadley circulation to equatorial anomalies of ocean temperature. Tellus, 18, 820-829.

_ 1969: Atmospheric teleconnections from the equatorial $\mathrm{Pa}$ cific. Mon. Wea. Rev., 97, 163-172.

Burkhardt, J. P., and A. R. Lupo, 2005: The planetary and synopticscale interactions in a Southeast Pacific blocking episode using PV diagnostics. J. Atmos. Sci., 62, 1901-1916.

Chang, C.-P., Y. Zhang, and T. Li, 2000: Interannual and interdecadal variations of the East Asian summer monsoon and tropical Pacific SSTs. Part I: Roles of the subtropical ridge. J. Climate, 13, 4310-4325.

Frankignoul, C., 1985: Sea surface temperature anomalies, planetary waves and air-sea feedback in the middle latitudes. Rev. Geophys., 23, 357-390.

Held, I. M., S. W. Lyons, and S. Nigam, 1989: Transients and the extratropical response to El Niño. J. Atmos. Sci., 46, 163-174.

Hendon, H. H., and D. L. Hartmann, 1982: Stationary waves on a sphere-Sensitivity to thermal feedback. J. Atmos. Sci., 39, 1906-1920.

Hoskins, B. J., and D. J. Karoly, 1981: The steady linear response of a spherical atmosphere to thermal and orographic forcing. J. Atmos. Sci., 38, 1179-1196.

Kalnay, E., and Coauthors, 1996: The NCEP/NCAR 40-Year Reanalysis Project. Bull. Amer. Meteor. Soc., 77, 437-471.

Kushnir, Y., W. A. Robinson, I. Bladé, N. M. J. Hall, S. Peng, and R. Sutton, 2002: Atmospheric GCM response to extratropical SST anomalies: Synthesis and evaluation. J. Climate, 15, 2233-2256.

Lau, N. C., 1997: Interactions between global SST anomalies and the midlatitude atmospheric circulation. Bull. Amer. Meteor. Soc., 78, 21-33.

McCreary, J. P., 1983: A model of tropical ocean-atmosphere interaction. Mon. Wea. Rev., 111, 370-387.

Nakamura, H., and T. Fukamachi, 2004: Evolution and dynamics of summertime blocking over the Far East and the associated surface Okhotsk High. Quart. J. Roy. Meteor. Soc., 130, 1213-1233.

Ogi, M., Y. Tachibana, and K. Yamazaki, 2004: The connectivity of the winter North Atlantic oscillation (NAO) and the summer Okhotsk High. J. Meteor. Soc. Japan, 82, 905-913.

Peng, S., L. A. Mysak, J. Derome, H. Ritchie, and B. Dugas, 1995: The differences between early and midwinter atmospheric responses to sea surface temperature anomalies in the northwest Atlantic. J. Climate, 8, 137-157.

Plumb, R. A., 1985: On the three-dimensional propagation of stationary waves. J. Atmos. Sci., 42, 217-229. 
Rasmusson, E. M., and T. H. Carpenter, 1982: Variations in tropical sea surface temperature and surface wind fields associated with the Southern Oscillation/El Niño. Mon. Wea. Rev., 110, 354-384.

Shaman, J., and E. Tziperman, 2005: The effect of ENSO on Tibetan Plateau snow depth: A stationary wave teleconnection mechanism and implications for the south Asian monsoons. J. Climate, 18, 2067-2079.

Smith, T. M., and R. W. Reynolds, 2004: Improved Extended Reconstruction of SST (1854-1997). J. Climate, 17, 24662477.

Tibaldi, S., and F. Molteni, 1990: On the operational predictability of blocking. Tellus, 42A, 343-365.

Wang, B., R. Wu, and X. Fu, 2000: Pacific-East Asian teleconnection: How does ENS0 affect the East Asian climate? J. Climate, 13, 1517-1536.

Wang, Y., 1992: Effects of blocking anticyclones in Eurasia in the rainy season (Meiyu/Baiu season). J. Meteor. Soc. Japan, 70, 929-951.
_ , and T. Yasunari, 1994: A diagnostic analysis of the wave train propagating from high-latitudes to low-latitudes in early summer. J. Meteor. Soc. Japan, 72, 269-279.

_ B. B. Wang, and J.-H. Oh, 2001: Impact of preceding El Niño on the East Asian summer atmosphere circulation. J. Meteor. Soc. Japan, 79, 575-588.

—, K. Yamazaki, and Y. Fujiyoshi, 2007: The interaction between two separate propagations of Rossby waves. Mon. Wea. Rev., 135, 3521-3540.

Webster, P. J., and J. R. Holton, 1982: Cross-equatorial response to middle-latitude forcing in a zonally varying basic state. J. Atmos. Sci., 39, 722-733.

Wiedenmann, J. M., A. R. Lupo, I. I. Mokhov, and E. Tikhonova, 2002: The climatology of blocking anticyclones for the Northern and Southern Hemisphere: Block Intensity as a diagnostic. J. Climate, 15, 3459-3473.

Ye, D., and R. Huang, 1996: Study about Mechanism of Drought and Flood around Changjiang River and Huanghe River (in Chinese). Shandong Science and Technique Press, 387 pp. 